\title{
A Critique of Overreaction Effect in the Global Stock Markets over the past three decades
}

\author{
Supriya Maheshwari ${ }^{1}$, Prof. Raj S. Dhankar ${ }^{2}$ \\ ${ }^{1}$ Research Scholar, Faculty of Management Studies, University of Delhi, India) \\ ${ }^{2}$ Dean, Faculty of Management Studies, University of Delhi, India)
}

\begin{abstract}
Overreaction Effect can be traced back to 1980's when DeBondt and Thaler (1985) argued that there existed a strong tendency for both low and high performing securities in one period to experience reversal in following years. Since then it has become one of the grey areas in finance and lead to an on-going debate on its existence. The current paper critically evaluates the work of various authors discussing the possible causes of the effect and its behavioural aspects.
\end{abstract}

Key Words:Behavioural Finance, Contrarian Strategy, EMH, Overreaction Effect,

\section{Introduction}

In 1670, Isaac Newton concluded that "What goes up must come down." Centuries later DeBondt and Thaler (1985) came out with the same conclusion in stock market proposing that there is a strong tendency for high performing securities in one period to experience reversal in following years, referring it as "Overreaction Effect". Since then it has become one of the grey area in finance. Overreaction Hypothesis asserts that stock market is subject to the waves of optimism and pessimism. Stock prices tend to deviate temporarily from their fundamental values; prices shoot up over good news and drops over bad news. However, over a period of time stock prices gradually reverts back to their fundamental values thereby suggesting that prices have overreacted in initial period and it subsequently corrects itself. The most interesting application associated with Overreaction Hypothesis is the potential to earn abnormal profits by implementing contrarian strategy that is purchasing low performing securities and selling high performing securities in advance of any subsequent reversals. This possibility acts as a serious blow to Efficient Market Hypothesis (EMH) (Fama 1970) that claims that stock prices accurately reflects all the available information at all times, and hence there is no possibility to earn excess returns in the market. Subsequent studies focussed on testing the overreaction hypothesis and explaining the overreaction effect. This has resulted in development of several theoretical and behavioural models.

The purpose of the study is to review the available literature on the overreaction effect. Section two gives the brief review of the effect.Sectionthree and four discuss the various arguments in favour and against the presence of the overreaction effect. Section five provides the possible explanation of overreaction effect based on behavioural models. Section six provides empirical evidences on overreaction effect in various international stock markets and finally section seven concludes.

\subsection{Overreaction Hypothesis}

\section{Overreaction Effect : An Overview}

DeBondt and Thaler (1985) argued that stock market overreacts to information in past earnings and/or security prices, at the expense of longer-run trends. As a result of this, investors can earn abnormal profits in longer horizon by buying up undervalued stocks and selling overvalued stocks. The motivation behind the research of DeBondt and Thaler (1985) was to investigate the relationship and link between the market behaviour and psychology of individual decision making. Based on the work of Kahneman and Teversky (1982), they suggested that investors do not follow Baye's rule and most people "overreact" to unexpected and dramatic news events.

DeBondt and Thaler (1985) explained the Overreaction effect as follows:

"If stock prices systematically overshoot, then their reversal should be predictable from past return data alone, with no use of any accounting data such as earnings. Specifically, two hypotheses are suggested:

(1) Extreme movements in stock prices will be followed by subsequent price movements in the opposite direction.

(2) The more extreme the initial price movement, the greater will be the subsequent adjustment."

To verify these hypotheses, they observed the NYSE monthly return data for the period 1926-1982 by focusing on stocks that have experienced either extreme capital gain or losses over the period of last five years. The methodology used by DeBondt and Thaler (1985) involved the construction of two portfolios: Winner and Loser. Winner portfolio was composed of extreme high return securities and Loser portfolio was composed of 
extreme low return securities. Empirical results of the study shows that on an average the loser portfolio outperformed the market by $19.6 \%$ and winner underperform the market by $5 \%$. Hence the average cumulative residual between the extreme portfolios (Winner- Loser) equals to significant gain of 24.6\%. This work of DeBondt and Thaler (1985) was the first attempt to apply a test for a behavioural principle to the stock market. This phenomenon is also known as Winner-Loser Effect. The overreaction hypothesis generated much of the interest in subsequent years. Brown and Harlow (1988) further extended the study of DeBondt and Thaler (1985) by studying the relationship between the magnitudes of the reaction with the amount of time of initial price change. They formulated the "Overreaction Hypothesis" as following three propositions:

Directional Effect: Extreme Movements in equity prices will be followed by movements in opposite direction. Magnitude Effect: The more extreme the initial price change, the more extreme the offsetting reaction.

Intensity Effect: The shorter the duration of the initial price change, the more extreme the subsequent response. Subsequent research by Fama and French (1988) and Poterba and Summers (1988) also finds results consistent with the predictability in stock returns, supporting the Debondt and Thaler (1985) findings. Fama and French reported in 1988 that $25 \%$ to $45 \%$ of the variations in monthly returns over a period of three to five year are predictable using past returns. Jegadeesh and Titman (1993) had thrown new light on the influential work of Debondt and Thaler (1985) and found evidence in favour of short term momentum effect and long term reversals.In addition to long term overreaction documented by DeBondt and Thaler (1985), many studies have documented the existence of short term overreaction effect. Brown and Harlow (1988) also stated that the tendency of stock market to overreact is best regarded as asymmetric short term phenomenon. Howe (1986) proved that based on large price depreciation over a period of one week, the winners exhibit abnormal negative returns up to one year post portfolio formation. Bowman and Iversan (1998) argued that even though the evidence on the cause of long run return reversal are conflicting, the evidences are more consistent in favour of overreaction as short term reversals.

\subsection{Stock Overreaction and Implication to EMH}

Efficient Market Hypothesis (EMH),isperhaps the most interesting, well studied and controversial topic in all the social sciences. Fama in 1970 summarised EMH as "prices fully reflect all available information" and markets are rational and efficient. On the basis of relevant information, market is divided into three stages: weak form, semi strong form and strong form. According to EMH, stocks will always trade at their fair value and will give normal returns only. Hence, it is impossible to get abnormal returns based on the information available about the past. In the first decade after its formation, EMH was widely accepted by financial economists. This had made investors to believe that EMH restricts their ability to earn abnormal profits. However in the recent years, researchers have started challenging the weak form of market efficiency. Overreaction Hypothesis proposes that stocks that perform best (worst) over an initial period tend to perform worst (best) in the subsequent period. This behaviour is generally recorded due to market participants, who overreact to the new dramatic event in a way that extremely negative news pulls the stock prices much below their true value and extraordinary positive news pushes the stock prices well above their fundamental value. Over a period of time, investors realize their mistakes and take corrective actions. This leads to the change in the prices in the opposite direction of the initial movement and prices revert back to their true fundamental levels. Hence, it is possible to earn abnormal profits by adopting contrarian strategy of purchasing past low performing securities and selling past high performing securities. This suggests that, there exists some predictability in the stock market and hence violating the weak form of market efficiency. This has led to an on-going debate on stock market efficiency and researchers have not yet reached a consensus about whether financial markets are efficient or not.

\section{Critiques Of The Overreaction Effect}

The proposition of the overreaction hypothesis by DeBondt and Thaler (1985) has generated much interest and controversy in the subsequent years. DeBondt and Thaler (1985) suggested that the results of the study evidence the irrationality or irrational behaviour shown by the investors in stock markets. They suggested that when investors revise their prospects, they tend to overweight recent information and underweight past information. This leads to excessive optimism about good news and extreme pessimism over bad news. This causes stock prices to depart from their fundamental values. However different authors were sceptical about the hypothesis and have presented different explanations for the same.

\subsection{Overreaction or Time Varying Risk}

DeBondt and Thaler (1985) assumed that the risk level does not change between portfolio formation and test period. However, Chan(1988), Ball and Kothari (1989) and others have argued that the prior performance do changes the risk of winner and loser firms and the risks does not remain constant over the period of time. 
Chan (1988) argued that both winner and Loser portfolio experiences large changes in market value during the rank period. He argued that the stocks with the series of negative abnormal returns will experience an increase in their equity betas and thus increased expected returns. The results of the study were consistent with the risk change explanation as large changes in betas from rank period to the test period were observed. The loser's beta increases after a period of abnormal loss and the winner's beta decreases after a period of abnormal gain. Further, after accounting for the changes in betas of losers and winner portfolios from rank period to test period, contrarian strategy earns only small, non-economical significant abnormal returns.

Similar and confirmatory evidence was presented by Ball and Kothari (1989), who although using a different methodology as compared to Chan (1988), finds that negative serial correlation in returns are entirely due to variation in relative risks. They presented a novel argument for negative serial correlation by taking into consideration the changes in leverage. They argues that as leverage is a decreasing function of past equity returns, and equity betas in turn are increasing function of leverage, hence a series of negative abnormal returns will increase the leverage which will increase the equity beta of the firm leading to increased expected return on the stock. The results of the study showed severe changes in betas, between formation and the test period. Their results, proved the importance of time-varying risk as an explanation behind the mean reversion of returns.

Jones (1993) reconciled the work of DeBondt and Thaler (1985, 1987), Chan (1988) and Ball and Kothari (1989) and suggested that the simple leverage effect as reported by Chan (1988) could not account for the positive covariance. Instead the evidence of overreaction could be attributed to the pattern of market movements. Assuming stocks returns as described by market model, asymmetric risk exposure was observed, that is, the winner betas tends to be relatively higher in up markets and lower in down markets. Jones suggested that the apparent pattern in US stock returns and contrarian profits were consistent with rational time varying expected returns.

\subsection{Overreaction: A manifestation of Size Effect}

Zarowin $(1989,1990)$ challenged the DeBondt and Thaler's (1985) findings and evidence on stock market overreaction in the light of size phenomenon. Size effect is a well-known anomaly in the academic literature. Size effect refers to the tendency of small capitalization shares to outperform the large capitalization shares over the longer horizons. Zarowin (1990) proposed that it is the differential size that drives the Winner vs. Loser phenomenon rather than the assumed investor overreaction. When DeBondt and Thaler (1985) study was replicated, results were found to be consistent with the hypothesis as poorest earners were found to outperform the best earners stocks. However, when size was controlled, losers outperformed winners only in the month of January. He further analyses the periods when were smaller than winners; and periods when losers were smaller than winners. The results indicated that when losers were smaller, they outperformed the winners and when winners were smaller, they outperformed the losers. This was consistent with size phenomenon but inconsistent with the overreaction phenomenon. Hence, Zarowin (1990) concluded that the Winner -Loser phenomenon observed by DeBondt and Thaler is another manifestation of size effect documented by previous studies.

\subsection{Microstructure Effects or Overreaction}

Another attack on overreaction effect comes from those who studied bid-ask effect. Kaul and Nimalendrum (1990) and Conrad and Kaul (1993) attempted to show that most of the returns claimed by overreaction effect are caused by measurement errors in prices in the form of bid-ask spread. Loser firms being small and low priced firms have higher bid-ask spread as well as higher chances of non-trading. This leads to spurious autocorrelation. The above authors also criticised the use of cumulative abnormal returns methodology adopted byDeBondt and Thaler (1985) as this cumulates the upward biases along with the returns and exaggerate the observed mean reversion in stock prices. Instead, they recommended the use of buy and hold return metric. Ball, Kothari and Shankeen (1995) also argued that the losers stocks picked by DeBondt and Thaler $(1985,1988)$ were low priced. The low priced loser stocks were found to be extremely sensitive to microstructure and liquidity effects. Theyfurthercriticized DeBondt and Thaler (1985) choice of December as the portfolio formation month. They reported that when June and August were used as portfolio formation month, the results were found to be inconsistent with the overreaction hypothesis.

\subsection{Overreaction or January Effect}

Starting from the study Of DeBondt and Thaler (1986), Zarowin (1990), Jegadeesh (1991), Conrad and Kaul (1993), Pettengill and Jordan (1990), Chopra, lakonishok and Ritter (1992) observed strong January seasonal in the price reversals. Pettengill and Jordan (1990) reported that all the reversals observed by overreaction hypothesis were restricted to the month of January. In fact, when losers and winner portfolios were matched with comparable size portfolios, Zarowin (1990) observed that the performance differentials only exist in the month of January. Conrad and Kaul (1992) using buy and hold strategy also claimed that all the observed 
abnormal returns in the month of January was due to January effect rather than any past performance of the securities.

\section{The Overreaction Hypothesis Restored}

The critiques of Chan (1988), Ball and Kothari (1988), Zarowin (1990), Conrad and Kaul (1993) and others have not gone unchallenged. De Bondt and Thaler (1987) revaluate the overreaction hypothesis to study the size, January effect as well as time varying risk premia. They provided an additional support in favour of overreaction hypothesis and reported evidences that were inconsistent with two alternative explanations based on firm size and the difference in risk as measure by CAPM beta. They argue that though the estimated beta for loser portfolio was 0.22 greater than the winner beta, this risk difference was insufficient to explain the average annual return of $9.2 \%$ of arbitrage portfolio. This rejects the plausible difference in risk explanation for WinnerLoser effect. Further they also reported that as the firm in both extreme quintiles were smaller than those in middle portfolio but were found not to be unusually small. The average market value for quintile was thirty times larger than average market value for the smallest quintile as ranked by market value. This rejected the small firm effect as a plausible explanation of overreaction effect.

Chopra, Lakonishok and Ritter (1992) further presented evidence consistent with overreaction hypothesis and dismissed size based explanations. They confirmed that the statistically significant degree of overreaction exists of about 5-10\% per year even after controlling for risk and size. Focussing initially on the risk adjustments, Chopra et al critically examined the work of Ball and Kothari (1989) and pointed out that the Ball and Kothari estimates of degree of overreaction were underestimated due to sample selection bias. Chopra et al approaches the problem of controlling for risk by grouping companies into equivalent risk class beta vitile for the test period of 1926-1981. After adjusting for size when calculating abnormal returns, they observe the presence of an economically significant overreaction effect. The effect was found to be much stronger in small firms compared to large firms. This was due to predominant individual investors in small firms, who might overreact. Alonso and Rubio (1990), Albert and Henderson (1995) and Ahmad and Hussain (2001) also dismissed the notion that the return reversal is explained by the firm size effect. Albert and Henderson (1995) claims that the 'size matching methodology' used byZarowin (1990) was biased in a way the firms were ranked. Using different methodology to construct control portfolios, they observed an overreaction effect that was distinct from the size effect.

With regard to bid-ask spread, Loughram and Ritter (1996) challenged the findings of Conrad and Kaul (1993). Authors provided direct evidence showing that the DeBondt and Thaler (1985) findings were not driven by the use of cumulating single period returns as compared to buy and hold returns. With the help of direct tests, they further found little differences in test period returns whether CAR (Cumulative abnormal returns)as proposed by DeBondt and Thalerorbuy and hold returns were used. Loughram and Ritter further claimed that the buy and hold method provides a sharper distinction between the portfolios, but once portfolios are selected, both CAR strategy and buy and hold Strategy will provide similar results. Furthermore, they also suggested that the differences in loser and winner thirty-sixth CAR results as reported by Conrad and Kaul (1993) were different from DeBondt and Thaler (1985) mainly due to survivorship bias in Conrad and Kaul (1993) sample.

Further, Dissanaike (1997) using the methods employed by Chan (1988) and Ball and Kothari (1989) to control for time varying risk, founds little evidence supporting the claim that changes in betas leads to price reversals. Moreover, by restricting the sample to large and better knowncompaniestominimize the biases created by bidask effect and infrequent trading, significant abnormal returns were observed. This shows that the existence and the causes of the overreaction effect are still open to debate.

\section{Behavioural Finance: A New Perspective}

Behavioural finance offers unconventional explanations on the most important question of, why prices deviate from their fundamental values. According to Hirshleifer (2001), behavioural finance is based on the claim that human behaviour and perceptions represents the two crucial elements of financial decision making. In addition, it focussed an application of psychological and economic principles for the improvement of financial decision making. This has led to the search for new models and ideas that may be able to predict and explain various market anomalies and behaviour from various psychological biases. The following section provides some of the behavioural explanations the short term under reaction and long term reversals in stock prices.In order to explain the long term overreaction, Barberis et al (1998) presented a model that combines conservatism bias with representative heuristic. Barberis et al argued that representative heuristic may lead investors to mistakenly conclude that firms realizing extraordinary growth will continue experience such growth in future. This behavioural tendency will lead to long horizon negative returns for stocks with consistently high returns in the past. Daniel, Hirshleifer and Subrahmanyam (1998) assumed that investors are overconfident about their private information and overreacts on that. Due to self-attribution bias, investor's overconfidence increases 
following the arrival of confirming news. The increase in overconfidence promotes the initial overreaction and generates the return momentum. The overreaction in prices will eventually be corrected in the longer run as investors observed future news and realized their mistakes, leading to long run reversals.Hong and Stein (1999) presented a model that was based on initial under reaction to information and subsequent overreaction that eventually leads to stock price reversal in the long run. The model defines two types of investors: news-watchers and momentum- traders; news watchers rely purely on their private information and momentum-traders rely exclusively on the information in past price changes. The prices are initially driven by news-watchers and then the news gradually gets transmitted to the market where momentum traders react to the news. This leads to initial under-reaction till the time momentum-traders didn't react to the news and subsequent overreaction when they react. In long run this overreaction disappeared and price reverts back to their fundamentals in long run. As it can be seen there exist a number of theories in behavioural sciences that tries to give explanation on the presence of positive long term reversals. According to behaviourist, contrarian profits are due to market inefficiency and investors non-rational behaviour. However, Locke and Gupta(2009) has pointed out that it is still unclear whether such violations of market efficiency can be given a behavioural explanations or these are the results of rational response of investors towards the market constraints. Hence, lot of research is needed on the behavioural explanation of investor's overreaction and the kind of behavioural patterns that generates such reaction.

\section{International Empirical Evidences Of Overreaction Effect}

The empirical evidences presented so far was concentrated mainly on US stock market. However, as the case in most other financial studies, once the phenomenon has been detected in the US market, it is further tested in other financial markets. It is important to examine the overreaction effect in international equity markets as the strength of overreaction effect may depends on various market characteristics and the evidences of overreaction effect in different markets and time periods would make for a strong argument against data mining.In the UK Stock market Campbell and Limmack (1997) and Dissanaike (1997) found evidence in favour of overreaction hypothesis. However, Clare and Thomas (1995) examined the Overreaction using the UK data for the period from 1955-1990 showed a very weak overreaction effect in UK stock market. They concluded that these abnormal returns were due to the size effect, as claimed by Zarowin (1990). In stock markets other than US and UK, Alonso and Rubio (1990) reported the presence of strong overreaction in Spanish equity market for the time period between 1967 and 1984. Overreaction in Spanish stock market was found to be systematic, with winners losing as much as losers winning and the effect gets stronger when longer formation and testing periods were used. In contrast, Forner and Marhuenda (2000) reported the results against the overreaction effect in Spanish equity market for the sample period from January 1963 to December 1997. The discrepancies between the studies were due to different methodology and sample period used. Alonso and Rubio used both non overlapping formation and test period, in contrast to non-overlapping test periods only by Forner and Marhuenda. Stock (1990) for German, Swallow and Fox (1998) for New Zealand stock market also confirmed the presence of overreaction effect. Bacmann and Dubois (1998) also reported that the standard contrarian strategy in all states of nature, lead to smaller yet significant profits in France. They further reported that the profits computed were stronger when market was strongly bullish.

However, in Australian and Canadian stock markets, the evidence in favour of overreaction effect was found to be weak. Brailsford (1992) using the Australian stock market data revealed that there exists no mean reversion in the returns of extreme portfolios. Kryzanowski and Zhang (1992) investigated the overreaction effect in Canadian Stock Market and found results inconsistent with overreaction effect using the test and formation period of 1, 2, 3, 5, 8 and 10 years. Unlike DeBondt and Thaler (1985), there exists insignificant reversal behaviour for winner and loser over longer formation and test periods.

Richard (1997) conducted quite a different study by using total returns of sixteen national market indices to form loser and winner portfolio, assuming the markets are well integrated with common international risk factors. He found statistically insignificant positive autocorrelation in short horizon of one year or less. However, for longer horizon of three to four years, losers outperformed winners. Further, winner-loser reversals were found to be larger among smaller markets; this may be due to market imperfections in smaller and emerging markets. Baytas and Cakici (1999) examined the seven developed US, Canadian, Japanese, French, Italian, German and UK stock markets and found strong evidence of overreaction effect in two and three year period for all countries except USA and Canada..Most of the previous Overreaction Hypothesis testing's were concentrated on developed stock markets. In fact only few studies included emerging markets in their samples. Da Costa (1994) came up with the findings in agreement to overreaction hypothesis in Brazilian stock market. The empirical results were found to be consistent with overreaction effect. Moreover, the overreaction effect in Brazilian stock market was found to be asymmetric in nature, as only the values of winner portfolio have reverted. Strong evidence in favour of the effect was also observed in Asian stock markets that include: India, Malaysia, Sri Lanka and China stock markets. Ahmad and Hussain (2001) and Ali et al (2011) reported the 
overreaction effect and seasonality in the stock returns of Malaysia Kuala Lumpur Stock Exchange (KLSE). Ali et al (2011) study also highlighted that the overreaction behaviour in Malaysian stock market was more pronounced in the period prior to 1997 Asian financial crises and had gradually diminished and became insignificant during the recent time period. Strong asymmetric overreaction effect was also observed by $\mathrm{Wu}$ (2004) in China stock market, Gunasekarage and Power (2005) for Colombo stock exchange (Sri Lanka), Locke and Gupta (2009) and Tripathi and Aggarwal (2009) for Indian stock market. In addition, a small number of studies also reported evidences in favour of overreaction effect in Africa and Middle-East stock exchanges. These includes Page and Way (1992) and Hsieh and Hodnett (2011) for South Africa, Dhouib and Abaoub (2007), Bildik and Gulay (2007) for Turkey, Saleh (2007) for Jordan and Ismail (2012) for Egyptian stock market. Hsieh and Hodnett (2011) test results also suggested that, there exists a saturation point for the past winners and a loser to continue their trends and the mean reversal take place once that saturation point is reached. In addition, authors performed a correlation analysis that revealed that winner and loser portfolio accumulates abnormal returns in opposite direction that were negatively correlated even when the returns of winners, losers and markets were positively correlated. The regression analysis supported the argument that mean reversals were more likely to take place when investors are less confident about the future prospects of the economy. Overall the results of these studies violate the weak version of EMH and confirm the possibility of stock returns on the basis of historical recordings without using any accounting data in respective stock markets. However, there are some important caveats to this conclusion. Firstly, many of the studies in emerging markets reported non-significant results in favour of overreaction effect; still they claimed them to be economically significant. Secondly, small sample composition of several studies including Dhouib and Abaoub (2007) of 30 stocks and Bildik and Gulay (2007) of less than 100 stocks, raises doubts on the reliability of the results. Further, studies such as Ahmad and Hussain (2007), Bildik and Gulay (2007) andDhouib and Abaoub (2007), includes ten years or less data, are also unlikely to yield reliable results.

\subsection{Scope for future research}

\section{Inferences}

This paper discusses the literature review of overreaction effect and its various causes. One of the major limitationsobservedin the literature is that, most of the statistical overreaction evidences are concentrated mainly for the highly developed market and very few focussedon less developed market. However, less developed and emerging markets are characterized by more predictability, thin trading and are dominated by less sophisticated investors who do not respond to information instantaneously. This leads to more profitable contrarian strategy. Further, the evidence of contrarian profits on such markets would be of more interest to investors as it leads to higher abnormal profits. Hence, there exists a huge gap in existing literature. We need more empirical research to re-examine the robustness of the overreaction effect not only in developed markets but in less developed and emerging markets. The overreaction effect could also be further tested in financial markets other than equity. Also a comparative study on the strength of such contrarian profits between developed and emerging market could be undertaken as a future course of research to understand the if significant difference exist, in the investing behaviour of investors in the two different types of markets. This all provides great opportunities to researchers to look into the area with new outlook and different perspective as well.

\subsection{Conclusion}

In the stock market literature, a very well-known and widely accepted preposition claims that the movement of a change in share prices is best characterized by random walk. However, contrary to the argument of the hypothesis, a great deal of evidence has been discovered that future prices are predictable. There exists unusual occurrence or abnormality in smooth pattern of stock market. EMH has been unable to explain the existence of such anomalies. DeBondt and Thaler (1985) observed one such anomaly and referred it as "Overreaction Effect" and was claimed as one of the most important anomalies investigated during 1980's. Since its existence, overreaction effect has been re-examined frequently and has been challenged on various factors. Despite the various challenges the overreaction effect has been recognized as an unresolved dispute. This literature review highlights the work of various authors and it provides an understanding to the young researchers in the respective field. Till date the studies on overreaction effect are mainly from the three perspectives: firstly on the existence of long term overreaction, secondly on the existence of short term overreaction and finally on the reasons and sources of contrarian profits. However, there exists conflicting and inclusive evidences on overreaction effect that has led to a puzzle in the literature that entreats for further research. 


\section{References}

[1]. Ahmad, Z., \& Hussain, S. (2001). KLSE Long Run Overreaction and the Chinese New Year Effect. Journal of Business,Finance and Accounting,28(1)\&(2), 63-112.

[2]. Albert, R., \& Henderson, G. (1995). Firm Size,Overreaction and Return Reversals. Quaterly Journal Of Business Economics,34, 60-80.

[3]. Ali, N., Nassair, A. M., Hassan, T., \& Abidin, S. Z. (2011). Stock Overreaction Behaviour in Bursa Malaysia: Does the length of formation Period matter. British Journal of Economics, 42-56.

[4]. Alonso A., R. (1990). Overreaction in the Spanish Equity Market. Journal of Banking and Finance,14, 469-481.

[5]. Bacmann, J. F., \& Dubois, M. (1998). Contrarian strategies and cross-autocorrelations in stock returns: Evidence from France. In Social Science Research Network Electronic Library, \& European Financial Management Association 1998 Meeting

[6]. Ball, R., \& Kothari, S. (1989). Non Stationary Expected Returns : implications for Test of Market efficiency and Srial Correlation in Returns. Journal of Financial Economics, 25, 51-74.

[7]. Ball, R., Kothari, S., \& Shanken, J. (1995). Problems in measuring portfolio performance:An application to contrarian Investment Strategies. Journal of Financial Economics 38, 79-107.

[8]. Barberis, N., \& R.Vishny. (1998). A model of Investor Sentiment2. journal of Financial Economics,49, $307-343$.

[9]. Baytas, A., \& Cakici, N. (1999). Do Market Overreact:international Evidence. Journal of Banking and Finance,23, 1121-1144.

[10]. Bildik, R., \& Gulay, G. (2007). Profitability of Contrarian Strategy :Evidence from the Istanbul Stock Exchange. International Review of Finance, 61-87.

[11]. Bowman, R., \& Iverson, D. (1998). Short run Overreaction in New Zealand stock market. Pacific Basin Finance journal 6, 475491.

[12]. Brailsford, T. (January 1992). A test For the Winner-Loser Anomaly In the Australian Equity Market: 1958-87. Journal of Business Finance and Accounting, 225-241.

[13]. Brown, K., \& Harlow, W. (1988). Market Overreaction:Magnituide and Intensity. Journal of Portfolio Management, 6-13.

[14]. Campbell, K. a. (1997). Long term Overreaction in the UK stock market and size adjustments. Applied Financial Economics, 7, 537548.

[15]. Chan, K. (1988). On the Contrarian Investment Strategy. Journal Of Business, 61, 147-163.

[16]. Chopra, N., Lakonishok, J., \& Ritter, J. (1992). Measuring Anormal Performance. Journal of financial Economics,31, 235-268.

[17]. Clare, A., \& Thomas, S. (October 1995). The Overreaction Hypothesis And the UK Stock Market. Journal of Business \& Accounting, 961-973.

[18]. Da Costa, N. (1994). Overreaction in Brazilian stock market. Journal of Banking and Finance,18, 633-642.

[19]. Daniel, K. a. (1998). Investor Psychology and security under-and Overreactions. Journal of Finance,53, $1839-85$.

[20]. DeBondt, F., \& Thaler.R. (1987). Further evidence on the investor overreaction and stock market seasonality. Journal of Finance, 42, 557-81.

[21]. DeBondt, W. F., \& Thaler, R. (July 1985). Does the Stock Market Overreact? The Journal of Finance, Vol XL, No 3, 793-805.

[22]. Dhouib, F. H., \& Abaoub, E. (2007). Does the Tunsian Stock Market Overreact? Asian Academy of Management Journal of Accounting and Finance, 3(2), 83-107.

[23]. Dissanaike, G. (1997). Do Stock Market Investors Overreact. Journal of Business and Accounting,24, 27-49.

[24]. Fama, E. (1970). Efficient Capital Markets: a review of theory and Empirical work. Journal of Finance,25, $383-417$.

[25]. Fama, E., \& French, K. (1988). Permanent and Temporary Components of Stock Prices. Journal of Political Economy,96, $246-273$.

[26]. Forner, C., \& Marhuenda, J. (n.d.). The Contrarian Strategy in the Spanish Stock Market. EFMA 2000, Athens. doi:10.2139/ssrn.251828.

[27]. Gunasekarage, A., \& Power, D. (2005). Stock Market Overreaction: Some evidence from Colombo Stock Exchange . Journal of Emerging market, 5-17.

[28]. Hirsshleifer, D. (2001). Investor Psychology and Asset Prices. Journal of Finance,56, 1533-1598.

[29]. Hong, H., \& Stein, J. (1999). A unified theory of underreaction, Momentum Trading and overreaction in asset markets. Journal of Finance, 54, 2143-2184.

[30]. Howe, J. (1986). Evidence on Stock Market Overreaction. Financial analysts Journal, July-August, 27-31.

[31]. Hsieh, H.-H., \& Hodnett, K. (2011). Tests of Overreaction Hypothesis and the Timing of Mean Reversals on the JSE Securities Exchange (JSE):the case of South Africa. Journal of Applied Finance and Banking, 107-130.

[32]. Jegadeesh, N., \& Titman, S. (1993). Returns to buying winners and selling losers: implications for stock market efficiency. Journal of Finance, 48, 65-91.

[33]. Jones, S. (1993). Another look at Time Varying Risk and Return in a Long Horizon Contrarian Trading Strategy. Journal of Financial Economics,33, 67-93.

[34]. Kahneman, D., Slovic, P., \& Teversky, A. (1982). Judgement Under uncertainity: heuristics and Biases. Cambridge University Press, 287-293.

[35]. Kaul, G., \& Nimalendrum, M. (1990). Price Reversals:Bid-Ask Errors or Market Overreaction. Journal of Financial Economics, 28, 67-93.

[36]. Kryzanowski, L., \& Zhang, H. (1992). The Contrarian Investment Strategy does not work in Canadian Markets. Journal of Financial and Quantitative Analysis, September, 383-395.

[37]. Locke, S., \& Gupta, K. (2009). Applicability of Contrarian Strategy in Bombay Stock Exchange. Journal of Emerging Market Finance, 165-189.

[38]. Loughran, T., \& ritter, J. (1996). Long Term Market Overreaction:the effect of Low Priced Stocks. Journal of Finance,51, 19591970 .

[39]. Page, M., \& Way, C. (1992/1993). Stock market Overreaction:the south african Evidence. Investment Analysts Journal, $35-49$.

[40]. Pettengill, G., \& Jordan, B. (1990). The Overreaction Hypothesis,Firm Size and Stock Market Seasonality. Journal of Portfolio Management, Spring, 60-64.

[41]. Poterba, J., \& Summers, L. (1988). Mean Reversion in Stock Prices: Evidence and Implications. Journal of Financial Economics, 22, 27-59.

[42]. Richard, A. (1997). Winner-Loser Reversals in National Stock Market Indices: Can they be explained? Journal of Finance, December.

[43]. Saleh, W. (2007). Overreaction:the sensitivity of defining the duration of formation period. Applied Financial Economics, 17 , 45-61.

[44]. Stock, D. (1990). Winner and Loser Anomalies in the German Stock Market. Journal of Institutional and theoretical Economics, 146(No.3), 518-529. 
[45]. Swallow, S., \& A.Fox, M. (1998). Long Run Overreaction on the New Zealand Stock Exchange. Commerce Division discussion paper, 48(48).

[46]. Tripathi, V., \& Aggarwal, S. (2009). the Overreaction effect in Indian Stock Market. Asian Journal of Business and Accounting, 2(1\&2), 93-114.

[47]. Wu, Y. (2004). Momentum Trading,Mean Reversion and Overreaction in Chinese Stock Market. HKIMR working paper No. 23, Honk Kong Institute for Monetary Research.

[48]. Zarowin, P. (1989). Does the stock market overreact to corporate earnings information? Journal of Finance,44, $1385-1399$.

[49]. Zarowin, P. (1990). Size ,seasonality, stock market and Overreaction. Journal of Financial and quantitative Analysis,25, 113-125. 